\title{
Spectrum of Oral Cavity Lesions Observed in 50 Cases - A Two Year Study
}

\author{
S. Srikanth ${ }^{1 *}$, J. Rajitha ${ }^{2}$
}

${ }^{1}$ Professor, Department of Pathology, Malla Reddy Institute of Medical Sciences, Hyderabad, Telangana, India

${ }^{2}$ Associate Professor, Department of Pathology, Chalmeda Anand Rao Institute of Medical Sciences, Karimnagar, Telangana, India

DOI: $10.36347 /$ sjams.2020.v08i10.036

| Received: 07.10.2020 | Accepted: 21.10.2020 | Published: 29.10.2020

*Corresponding author: Dr. S. Srikanth

Abstract

Original Research Article

Background: Oral cavity lesions are usually asymptomatic. Oral cancer is the most common type of cancer among males in India. Proper management of patients begins with an accurate diagnosis and histopathology is considered as the gold standard. Although the oral cavity lesions constitute only a small minority of pathological conditions, they are of great significance, as they have a potential to jeopardize the health and longevity of the patient. An adequate incision biopsy taken from an area representative of the lesion can provide over $98 \%$ diagnostic accuracy as to whether the lesion is malignant or not, when routine pathological techniques are used. Most oropharyngeal cancers in India present in advanced stages of malignancy. Materials $\&$ Methods: The present study is a prospective study done for a period of two years. All the oral cavity lesions are included in our study. Proper clinical history, radiological details if necessary and clinical examination were done in our study. Results: Out of the total 50 cases in our study, Squamous cell carcinoma was the most common lesion, contributing upto 14 cases. Male to female ratio was 4:1 and age group between 41-50 years contributed highest number of cases. Conclusion: Awareness should be created among people about the early approach to hospital, maintenance of oral hygiene by cultivating good oral habits, and periodic oral check-ups. Effective oral health programs for spread of knowledge and awareness, prevention, early diagnosis and management, and follow up of oral cancer must be implemented.

Keywords: Oral cavity, Squamous cell carcinoma, hemangioma.

Copyright (C) 2020 The Author(s): This is an open-access article distributed under the terms of the Creative Commons Attribution 4.0 International License (CC BY-NC 4.0) which permits unrestricted use, distribution, and reproduction in any medium for non-commercial use provided the original author and source are credited.

\section{INTRODUCTION}

Although the oral cavity lesions constitute only a small minority of pathological conditions, they are of great significance, as they have a potential to jeopardize the health and longevity of the patient [1]. Globally, about, 5,75,000 new cases and 3,20,000 deaths occur every year from oral cancer [2]. It is essential to establish an accurate diagnosis, to initiate optimal therapy for oral cavity lesions. An adequate incision biopsy taken from an area representative of the lesion can provide over $98 \%$ diagnostic accuracy as to whether the lesion is malignant or not, when routine pathological techniques are used.

Most oropharyngeal cancers in India present in advanced stages of malignancy.

Oral cancer is a major health problem in some parts of the world especially in developing countries. Oral cancer is the sixth most common cancer in the world whereas in India it is the most prevalent cancer. In India increase in incidence is seen in states like Uttar
Pradesh, Madhya Pradesh, Gujarat, Bihar, and Maharashtra.

Cancers of the oral cavity and hypopharynx are highly common in Asian countries. One-third of global cases and one-half of oral cancer-related deaths are reported from Southeast Asia. In certain countries, such as Sri Lanka, India, Pakistan, and Bangladesh, oral cancer is the most common cancer [3].

In parts of India, oral cancer can represent more than $50 \%$ of all cancers, and it is the most common cancer among male and the third most common among female population, which is related to the deleterious oral habits such as tobacco chewing, betel-quid chewing, tobacco smoking, reverse smoking, as well as other factors such as alcohol consumption, low socioeconomic status, poor hygiene, poor diet, and viral infections, chronic irritation from ill-fitting dentures, rough, or fractured teeth. The most common sites of occurrence of oral squamous cell carcinoma (OSCC) are buccal mucosa and tongue [4]. 
Oral cancer affects males more frequently than females, although the ratio is equalizing, and in recent times, increased number of cases is being reported in elderly females as well as young females. It predominantly affects middle-aged and older persons. However, the incidence of OSCC in persons under the age of 45 is increasing.

The etiology of oral cancer is multifactorial with the most important risk factors being tobacco, excess consumption of alcohol, and betel-quid usage. However, several studies in recent times report surprising increase in oral cancer in patients, often with no significant tobacco and alcohol exposure.

\section{Materials \& Methods}

The present study is a prospective study done for a period of two years and we diagnosed 50 oral cavity lesions. All the clinical and radiological details were considered. The most common age group involved was between 41-50 years and males were more commonly affected compared to females. Biopsy specimen was received from the respective departments and it was fixed properly and then submitted for grossing and other steps and observed under microscope.

\section{RESULTS}

Out of the total 50 cases, Squamous cell carcinoma was the most common lesion observed in our study contributing upto 14 cases and followed by one case of verrucous carcinoma and 2 cases of hemangioma (Tbale-1). The most common age group affected was in between 41- 50 years and male to female ratio was $4: 1$.

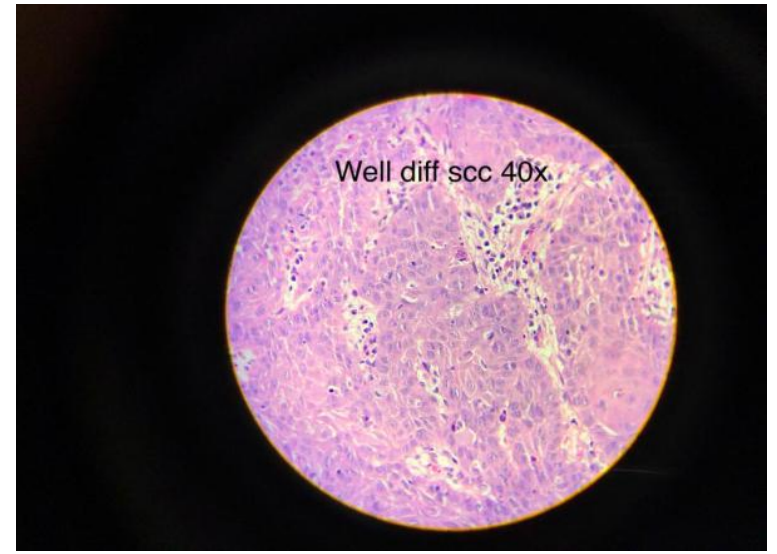

Fig-1: Sections showing sheets and nests of tumour cells and at places showing foacl invasion. - Well differentiated Squamous cell carcinoma [H\&E, 40x]

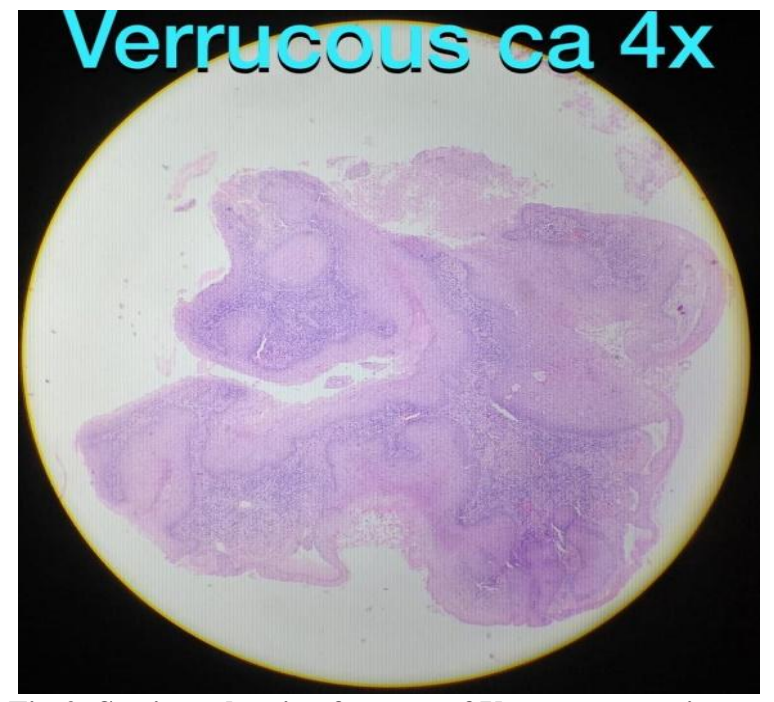

Fig-2: Sections showing features of Verrucous carcinoma [H7E, 4x]

Table-1: Showing various oral cavity lesions

\begin{tabular}{|l|l|l|}
\hline Serial No & Lesion & Number of cases \\
\hline 1 & Leukoplakia & 06 \\
\hline 2 & Pyogenic granuloma & 03 \\
\hline 3 & Chroinic non specific inflammation & 07 \\
\hline 4 & Hemangioma & 03 \\
\hline 5 & Sub mucous fibrosis & 04 \\
\hline 6 & Cystic lesions & 08 \\
\hline 7 & Pseudoepitheliomatous hyperplasia & 03 \\
\hline 8 & Verrucous carcinoma & 02 \\
\hline 9 & Squamous cell carcinoma & 14 \\
\hline Total cases & & $\mathbf{5 0}$ \\
\hline
\end{tabular}

\section{DISCUSSION}

Oral cancer is one of the ten most common cancers in the world. In India, it is the most common cancer among male and the third most common among female population. An estimated 378,500 new cases of intraoral cancer are diagnosed annually worldwide. In developed countries, oral cancer is less common but is the eighth most common form of cancer overall; however, the ranking varies a great deal among countries. For example, in areas of northern France, oral cancer is the most common form of cancer in men. The prevalence of intraoral cancer appears to be rising in many countries, especially in younger people [5].

Oral cancer affects males more frequently than females, although the ratio is equalizing, and in recent 
times, increased number of cases is being reported in elderly females as well as young females [6, 7]. It predominantly affects middle-aged and older persons. However, the incidence of OSCC in persons under the age of 45 is increasing $[8,9]$.

The etiology of oral cancer is multifactorial with the most important risk factors being tobacco, excess consumption of alcohol, and betel-quid usage [10]. However, several studies in recent times report surprising increase in oral cancer in patients, often with no significant tobacco and alcohol exposure.

OSCC accounts for $\sim 90 \%$ of malignant oral lesions and is widely recognized as the most frequently occurring malignant tumor of oral structures, and the mortality rate of OSCC is relatively high, with a 5-year survival rate of 50\% [11]. India has the world's highest number (nearly 20\%) of oral cancers with an estimated $1 \%$ of the population having oral premalignant lesions.

In the present study, increased incidence of OSCC was found in males than in females with a maleto-female ratio of $4: 1$ which is consistent with other north Indian studies on oral cancer. Males are more commonly affected compared to females by OSCC in both developed (male: female ratio 2.5:1) and developing (male: female ratio 3:1) countries, which may be due to easy acceptance of habits by males [12]. However, in recent time, this difference in gender distribution is reducing in the developed countries due to more females taking up tobacco-related habits including smoking [12].

Tobacco consumption is a major risk factor for oral and oropharyngeal SCC. There is a strong association between the use of smokeless tobacco and the risk of development of OSCC. Distinct cultural practices such as betel-quid chewing as well as varying patterns of the use of tobacco and alcohol are prevalent in Asian countries, which are important risk factors that cause oral cancer. The sociocultural norms and values also favor the easy availability of tobacco products. The advent of ready to use tobacco products and aggressive marketing attracts not only youths but also children. In India, the efforts of the Government for deterrence of tobacco products' use prove to be inadequate when looked at the easy availability of the products and their rampant use.

The most common sites of OSCC were buccal mucosa and GBS followed by alveolus, and the findings are consistent with other studies [13-15]. The tongue is considered as the most common site of occurrence of primary OSCCs in the developed countries, but in the developing countries, betel quid and/or tobacco chewing more commonly results in cancer of the buccal mucosa. This is mainly because of prolonged placement of the betel quid in the buccal pouch to obtain a maximum effect as the constituents of betel quid produce a sense of well-being and increased capacity to work by stimulation of parasympathetic nervous system. Similarly, smokeless tobacco tends to incite malignant degeneration at the site of tobacco placement.

Tobacco generates carcinogens (cancercausing chemicals) such as tobacco-specific nitrosamines (e.g., N-nitrosonornicotine, nicotinederived nitrosamine ketone, $\mathrm{N}$-nitrosoanatabine, and $\mathrm{N}$ nitrosoanabasine) and free radicals that can impede antioxidant enzymes such as glutathione S-transferase, glutathione reductase, superoxide dismutase, catalase, and glutathione peroxidase. Reactive oxygen species are generated in substantial amounts in the oral cavity during chewing.

Leukoplakia is a nonspecific clinical term used to describe a white patch on the oral mucosa that cannot be rubbed off. Leukoplakia does not correlate with any particular microscopic findings and may be related to a variety of lesions, from benign hyperkeratosis to carcinoma.

Verrucous carcinoma is a rare, low-grade, well-differentiated SCC of the skin or mucosa presenting with a verrucoid or cauliflower like appearance. It shows locally aggressive behavior and has low metastatic potential, a low degree of dysplasia, and a good prognosis.

\section{Conclusion}

There is increased incidence of premalignant lesions of oral cavity in the young generation due to increased intake of tobacco and other related intoxicants. A detailed clinical work up with histology can help in diagnosing more than $95 \%$ of the cases of oral cavity premalignant lesions and reducing morbidity and mortality due to malignant lesions. Oral Squamous cell carcinoma is the most common lesion in our study, which is more common in male population. Regular screening programmes about good dental hygiene and good habits should be encouraged to avoid oral premalignant and malignant lesions.

\section{REFERENCES}

1. Willium GS, Hine MK, Levy BM. A text book of oral Pathol. 4th ed. Philadelphia: WB Saunders Company; 1984.

2. Langdon JD, Russel RC, Williams NS, Bulstrode Arnold CJK. Oral and oropharyngeal cancer practice of Surgery. London: Hodder Headline Group; 2000.

3. Scully C. Cancers of the Oral Mucosa. Medscape; 2016.

Available from: http://www.emedicine.medscape.com/article /1075729overview\#a6. [Last accessed on 2017 Jun 23].

4. Krishna Rao SV, Mejia G, Roberts-Thomson K, Logan R. Epidemiology of oral cancer in Asia in 
the past decade - An update (2000-2012). Asian Pac J Cancer Prev. 2013; 14:5567-77.

5. Koo K, Barrowman R, McCullough M, Iseli T, Wiesenfeld D. Non-smoking non-drinking elderly females: A clinically distinct subgroup of oral squamous cell carcinoma patients. Int $\mathbf{J}$ Oral Maxillofac Surg. 2013; 42:929-33.

6. Koo K, Barrowman R, McCullough M, Iseli T, Wiesenfeld D. Non-smoking non-drinking elderly females: A clinically distinct subgroup of oral squamous cell carcinoma patients. Int $\mathbf{J}$ Oral Maxillofac Surg. 2013; 42:929-33.

7. Toporcov TN, Znaor A, Zhang ZF, Yu GP, Winn DM, Wei Q, et al. Risk factors for head and neck cancer in young adults: A pooled analysis in the INHANCE consortium. Int J Epidemiol. 2015; 44:169-85.

8. Beena VT, Binisree SS, Ayswarya T, Paikkadan I, Padmakumar SK, Sivakumar R. Oral squamous cell carcinoma in patients younger than 40 years: A 10 year retrospective study. Int J Sci Stud. 2016; 4:150-3.

9. Feller L, Lemmer J. Oral squamous cell carcinoma: Epidemiology, clinical presentation and treatment. J Cancer Ther. 2012; 3:263-8.

10. Scully C. Oral cancer aetiopathogenesis; past, present and future aspects. Med Oral Patol Oral Cir Bucal. 2011; 16:e306-11.
11. Jin X, Liu D, Zhao X, Zhou Y, Jiang L, Li J, Zeng $X$, Chen Q. Analysis of clinicopathological characteristics associated with the outcome of oral squamous cell carcinoma and the establishment of tissue microarrays. Oncology letters. 2016 Nov 1;12(5):3175-82.

12. Jayasooriya PR, Pitakotuwage TN, Mendis BR, Lombardi T. Descriptive study of 896 oral squamous cell carcinomas from the only university based oral pathology diagnostic service in Sri Lanka. BMC Oral Health. 2016; 16:1.

13. Singh MP, Kumar V, Agarwal A, Kumar R, Bhatt ML, Misra S. Clinico-epidemiological study of oral squamous cell carcinoma: A tertiary care centre study in North India. Journal of oral biology and craniofacial research. 2016 Jan 1;6(1):32-5.

14. Shenoi R, Devrukhkar V, Sharma BK, Sapre SB, Chikhale A. Demographic and clinical profile of oral squamous cell carcinoma patients: A retrospective study. Indian journal of cancer. 2012 Jan 1;49(1):21.

15. Addala L, Pentapati CK, Reddy Thavanati PK, Anjaneyulu V, Sadhnani MD. Risk factor profiles of head and neck cancer patients of Andhra Pradesh, India. Indian J Cancer. 2012; 49:215-9. 